\title{
Change in Uterine Shape
}

National Cancer Institute

\section{Source}

National Cancer Institute. Change in Uterine Shape. NCI Thesaurus. Code $C 92754$.

A variation in the dimensions of the uterus. 